\title{
Developing a Tool to Assess Competency to Consent to Psychiatric Hospitalization (KATOC): Reliability and Validity
}

\author{
Mi Kyung Seo ${ }^{1}$, Seung Hyun $\mathrm{Kim}^{2}$ and MinKyu Rhee ${ }^{3 凶}$ \\ ${ }^{1}$ Departments of Social Welfare and ${ }^{3}$ Psychology, Gyeongsang National University, Jinju, Korea \\ 2Department of Psychiatry, Guro Hospital, College of Medicine Korea University, Seoul, Korea
}

Objective The justification of informed consent requires that a patient be provided with the information necessary for deciding treatment and able to use such information based on reasonable thinking. The clinical decision to consider anyone who has mental disorder as incompetence without objective assessment does not only encroach human rights of the persons with mental illness, but seriously prevent them from being recovered. Hence the objective assessment of competency is needed in mental health. Our study aimed to develop the Korean Tool of Competency to Consent to Psychiatric Hospitalization and to analyze the reliability and validity of this tool.

Methods Totally 98 patients with mental illness who were hospitalized in mental hospital, participated in this study. For the subjects a questionnaire composing of 22 questions of understanding, appreciation, reasoning and expression of a choice was used. To investigate validity of this tool, MMSE-K, insight test, estimated IQ, BPRS were conducted. Its reliability and usefulness were examined with Cronbach's alpha, ICC and ROC analysis respectively and criterion related validation performed.

Results As results, this tool shows that agreement between raters is relatively high and the confirmatory factor analysis for constructive validation shows that the tool is valid. Also, for criterion related validation, estimated IQ, insight and MMSE are significantly correlated to understanding, appreciation and reasoning. However competence to express a choice did not show any significant correlation with criterion variables, nor showed BPRS any significant correlation with sub-competences.

Conclusion Our study developed the Korean Tool of Competency to Consent to Psychiatric Admission Treatment in the Mentally Ill, verified the reliability and validity of the tool and analyzed the optimum cutoff to distinguish between competence and incompetence in sub-competences. Korean Assessment Tool of Competency to Consent to Psychiatric Hospitalization (KATOC), analyzed the reliability and validity of this tool and presented the cutoff points by subarea. As a result, the reliability and validity of satisfactory levels were verified, the ROC analysis was implemented based on the clinical assessment and the cutoff points were found in understanding, appreciation, expression of a choice and reasoning. Such findings showed that the tool developed by researchers could be very favorably used in Korea.

Psychiatry Investig 2011;8:39-48

Key Words Informed consent, Competency to consent, Mental illness, ROC analysis, Korea Assessment Tool of Competency.

\section{INTRODUCTION}

In the health care, the justification of informed consent requires that a patient be provided with the information necessary for deciding treatment and able to use such information based on reasonable thinking. In other words, it is prerequisite for such justification that sufficient information is offered to a person who

Received: July 25, 2010 Revised: September 15, 2010

Accepted: September 30, 2010 Available online: October 30, 2010

$\triangle$ Correspondence: MinKyu Rhee, PhD

Department of Psychology, Gyeongsang National University, 900 Gajwa-dong, Jinju 660-701, Korea

Tel: +82-55-772-1264, Fax: +82-2-6230-9579, E-mail: rmk92@chol.com

(a) This is an Open Access article distributed under the terms of the Creative Commons Attribution Non-Commercial License (http://creativecommons.org/licenses/by$\mathrm{nc} / 3.0$ ) which permits unrestricted non-commercial use, distribution, and reproduction in any medium, provided the original work is properly cited. can make a decision in the circumstances that enables him/her to make a voluntary choice. However, when treating physical disease, the decision of an adult must be respected; in case of mental disease, he/she is judged to have no ability even without special reason, if he/she refuses to accept the treatment proposed. This means that different standards are applied to evaluate the autonomy of physical and mental diseases by clinician. ${ }^{1}$ However, the clinical decision to consider anyone who has mental disorder as incompetence without objective assessment does not only encroach human rights of the persons with mental illness, but seriously prevent them from being recovered.

In fact, a psychiatric patient has not been historically recognized as a decision-maker of life-related matters for the lack of recognition of their disorder and for the reason of disability of cognitive functions. Accordingly, WHO presented 25 principles 
for the protection of persons with mental illness, but showed the paradox of permitting a forced treatment for the reason of optimum treatment and protection from physically harming himself/herself or others at the same time. ${ }^{2}$ South Korea also has had the Mental Health Act from 1997 for the purpose of assuring of fair treatment, at least restrictive environment and human rights of persons with mental illness. The basic idea of this Act is that "everyone with mental illness shall be assured of dignity and value as a human being and be advised to always be hospitalized voluntarily." However, the $90.6 \%$ of all the patients hospitalized are in the state of involuntary hospitalization as of June 2007. ${ }^{3}$ According to the Korean Mental Health Act, it is possible to hospitalize a patient by force against his/her will regardless of his/her ability of consent, "if he/she has such a mental disorder that he/she has to be hospitalized" or if he/she needs to be hospitalized in order to protect his/her health or safety or other people's safety." Furthermore, once hospitalized by force, he/ she is regarded as continuously incapable throughout the process of treatment, which restricts his/her right of decision-making on discharge, transfer to another hospital and other participation in treatment to a large extent.

In the mental health, not recognizing the competency to consent of psychiatric treatment usually damages treatment relationships and a patient's self-esteem and prevents him/her from regaining his/her civil right by carrying out a responsible role. Accordingly, the mere existence of mental disease does not allow to assume that every patient is incapable, and even if incapacity is confirmed in some areas, such fact does not enable to restrict the competences in other areas ${ }^{4}$ so it is important making an effort to objectively assess a patient's competency to consent. Assessing competence to consent with objective and structured tools enables to especially assure the reliability of evaluation $^{5}$ and enables clinical experts to implement more ethical practice. Therefore, many researchers make continuous efforts to develop the tools high in reliability and validity. Recently, efforts are made to assess the competence to consent by selecting more efficient and effective tools in comparison to the validity, reliability and clinical usefulness. ${ }^{6.7}$ Efforts are made to make a differentiated evaluation by dividing consent areas into hospitalization, treatment, ${ }^{1,9,10-12}$ and participation in research. ${ }^{13-15}$

Clinically, social study, current and past histories, mental status examination, and memory test have been used to assess the competence to consent to hospitalization without objective tool. However, memory test solely serves to sort out who is absolutely incompetent, but cannot be used to identify the people who can remember any information but cannot understand or reasonably manage them. And mental status examination is a method to assess the adaptation functions of mental disease patients, but it alone does not discriminate competence status well. ${ }^{16}$

Accordingly, to develop useful assessment tool of competen- cy to consent a number of researchers ${ }^{5,17,18}$ conceptualize the competence as a multidimensional ability that can be divided into four sub-competences, not a single concept. First, the ability to express a choice is least stringent standard and its lack should be considered as incompetent on the whole. Second, the ability of understanding, focused on by most measurement tools, is a faculty to understand the information on mental illness. Such information includes his/her own mental status status, traits of proposed treatment, advantages and risks expected to get from treatment, alternative treatment and its advantages and risks. Third, the ability of appreciation is a faculty to apply the information understood to ones' own circumstances. To apply information to oneself, one has to admit that such information is necessary for oneself, so the ability of application is related to insight. Forth, the ability of reasoning is a faculty to compare advantages and risks logically in light of the seriousness of disorder and to decide whether to consent to or refuse treatment.

Such consent competences, including four sub-competences, are assessed with MacArthur Competency Assessment ToolTreatment (MacCAT-T), Structured Interview for Competency and Incompetency Assessment Testing and Raking Inventory (MacCAT-T) and Competency Interview Schedule. Each tool has merits and flaws, but MacCAT-T is a tool most used. This tool offers a mental disease patient the information on disease, including symptom, diagnosis and process, characteristics, advantages and dangers of proposed treatment and alternative treatment. Thereafter, the area-specific ability is assessed in terms of understanding, appreciation, reasoning and expression. ${ }^{19}$ It is reported that this tool showed a high interclass correlation coefficient (ICC) between raters ${ }^{20}$ and high relationships between symptoms, mental status and insight. ${ }^{12}$ However, the tool takes too much time to conduct test and give marks, so it is not easy to use the tool clinically on a routine basis, ${ }^{7}$ the tool needs to be more refined to get the definitions of reasoning and appreciation more clearly defined. ${ }^{6}$

Our study developed the Korean Tool of Competency to Consent to Psychiatric Hospitalization based on the MacCAT-T that is popularly used in relevant studies. To develop the tool, we composed the items representative of script, understanding, appreciation, expression and reasoning by the help of mental health professionals, revised grading standards and questions through preliminary survey and conducted this test. The objective of this study is to analyze the reliability and validity of this tool and to present the optimal cutoff points of competence and incompetence by sub-competence.

\section{METHODS}

\section{Participants}

The participants in this study were 98 psychiatric inpatients. 
The research ethics committee (Institution Review Board: IRB) in each hospital approved the study respectively. After describing the study to the participants, we obtained the informed consent from them. According to the DSM-IV criteria, there were 72 schizophrenia (73.5\%), 25 mood disorder (25.5\%) and one obsessive-compulsive disorder (1\%). Of these 54 (55.1\%) were male and $44(44.8 \%)$ were female with a mean age $36.58(\mathrm{SD}=$ $10.67)$ years old.

\section{Measures}

This study used mental status examination, insight examination, intelligence scale and clinical evaluations of psychiatrists to verify criteria-related validity of the tool to assess the ability to consent to hospitalization developed by our researchers.

\section{Korean Version of Mini-Mental State Examination}

$\mathrm{K}_{-M} \mathrm{MSE}^{21}$ is composed of Time Orientation (5 points), Place Orientation (5 points), Memory Registration (3 points), Memory Recall (3 points), Attention and Calculation (5 points), Language Function (8 points), Visuospatial Construction (1 point) and a total of 23 items.

\section{Schedule of Assessment of Insight}

To assess insight, this study used a scale developed by $\mathrm{Da}-$ vid. ${ }^{22}$ This measurement tool, a self report scale of a total of seven items, is aimed to measure the three dimensions on insight. The tool is composed of 2 items on Treatment Adherence, 3 items on Awareness of Illness and 2 items on whether to Re-labeling of Psychotic Phenomena. The highest and lowest scores of insight are 28 and 0 respectively. Cronbach's Alpha coefficient is.81.

\section{Estimated intelligence}

To assess the estimated intelligence of an individual, the estimated intelligence was calculated using 4 of 11 subscales of the K-WAIS ${ }^{23}$ (Korean-Wechsler Adult Intelligence Scale). 1) Information: It is composed of 29 items, measures the extent of the basic knowledge an individual possesses. 1 point is given to the item a right answer is given to, and the highest mark is 29 points. 2) Vocabulary: It is composed of 35 words list. This subscale, an important index indicating general intelligence, measures the extents of learning ability and general concept. The points from 0 to 2 are given according to the grading criteria standardized. 3) Picture arrangement: It is composed of 10 items, picture arrangement is made using 10 sets of picture cards are used. This subscale measures the understanding and planning competences of the whole circumstances. 4) Block design: It is composed of 9 items, block design uses 9 cards and 9 wooden blocks (red and white cubes). This subscale is used to measure perceptual organization ability, spatial representation ability and visual-mo- tor coordination ability. The split-half reliability of subscales was obtained by calculating out the reliability coefficient between two parts of the test and correcting it according to the SpearmanBrown formula. The average split-half reliability for the whole ages comprises Information of .93, Vocabulary of .93, Picture arrangement of .72 and Block design of .88 .

\section{Brief Psychiatric Rating Scale}

The brief psychiatric rating scale (BPRS), developed by Overall and Gorham, ${ }^{24}$ is used to assess how serious mental disease symptoms are. This scale of 7 points (0-6) measures a total of 18 items, i.e. Somatic Concern, Anxiety, Emotional Withdrawal, Concept Disorganization, Guilty, Tension, Mannerism \& Posturing, Grandiosity, Depression, Hostility, Suspiciousness, Hallucination, Motor Retardation, Uncooperativeness, Unusual thought content, Blunted Affect, Excitement, Disorientation $(0=$ none; $1=$ very light; $2=$ light; $3=$ middle; $4=a$ little serious; $5=$ serious; $6=$ =very serious). Marks are given by adding up the marks corresponding to items and range from 0 to 108 points. Cronbach's Alpha coefficient is 0.902 .

\section{Evaluation of hospitalization ability to consent by experts}

The expert panel, including a doctor in charge, measured the hospitalization consent competences of patients: $0=$ no ability; 1 (a few); 2 (many). They evaluated patients' competency based on the clinical assessment such as interview with patients and their primary care takers, and observation on patients' behaviors.

\section{Procedures to develop the tool}

The tool to assess hospitalization consent competences was developed by developing scripts, drawing up questionnaires, conducting and revising preliminary tests and conducting the main test. Specifically, each stage is as follows:

1) Script development: We drew up a script that contained the general psychiatric symptoms (concentration reduction, sleeplessness, gloom, uncertainty, auditory hallucination etc), treatment method (medication), treatment merits (symptom improvement), problems non-compliance (symptom deterioration, recurrence etc), merits at the time of hospitalization (regular medication, parallelism with other treatments etc). Symptoms were not restricted to a certain illness, and a wide range of treatment methods, merits and problems were presented. They were applicable to any patient with mental illness. This script was composed of 13 sentences of about 17 lines that can be understood by any person who graduated from primary school. It took approximately 1 minute 30 seconds to 2 minutes to read the script.

2) Development of question items: The items were made to question the script content. The items representative of each area were developed by collecting and analyzing the tools used for 
assessing the hospitalization decision-making ability of patients through literature review and by deciding the areas of the ability to consent to hospitalization through the discussion of experts. The items developed for the first time amounted to a total of 21: 5 items (understanding); 7 items (appreciation); 3 items (expression of a choice); 6 items (reasoning). Thereafter, a preliminary test was conducted, inappropriate items were deleted or revised through the discussion of experts, and one item was added to the expression of a choice. Finally, the tool to assess the ability to consent to hospitalization, developed by researchers, was composed of a total of 22 items: 5 items on comprehensive ability, 7 items on appreciation, 4 items on expression of a choice and 6 on reasoning.

3) Preliminary study: Two raters conducted a preliminary test for 5 hospitalized patients with schizophrenia. The preliminary test used 21 questionnaires on the competence to consent that were primarily developed by researchers. We discuss on the results and revised questionnaires, script and grading criteria. At this time, patients' answers were transcribed in maximum detail by raters. In questionnaires, the items were deleted or revised that patients were hard to answer or could be misunderstood or raters were hard to assess, and the items were complemented that were deemed to be additionally necessary. Grading criteria were divided in more detail by discussing problems based on the opinions of 2 raters who interviewed patients and assessed their answers respectively. Then we adjusted the grading criteria in order to minimize the discrepancy among the raters.

4) Implementation and grading of the main study: The patients admitted in mental hospital had a test conducted by 12 raters that had master degree or higher in mental health care sector. For consistent testing and grading, test developers carried out training for raters, who communicated with the developers at any time, when questions appear during testing and grading. To determine the reliability between raters, the transcripts were allotted to the two other raters who had participated in develop the test and were remarked by them.

A script on the general symptoms (concentration reduction, sleeplessness, uncertainty, abnormal behavior, auditory hallucination etc) and the necessity for medication and hospitalization etc) was read to them. The script was read not mechanically, but as if a story were slowly told, in a colloquial style in order patients to be easy to understand, important words in the script were emphatically read to them.

Thereafter, to assess their competences of understanding, they were asked in 5 items about how well they remember and understand symptoms, proposed treatment, treatment's advantages and dangers, comparison with alternative treatment etc. Each item was rated in 0-2 points, so the maximum total mark amounted to 10 points. To assess appreciation, they were asked in 7 items about whether they thought treatment and hospi- talization were necessary, which symptoms they thought would be improved and which problems they thought would occur. Although the patients did not agree with the proposed treatment, he/she presented reasonable reasons, we evaluated he/ she has competence of appreciation. Each item was measured in $0-2$ points, so the maximum total mark amounted to 14 points. The competences of expression and reasoning were assessed together. First, to assess the competence of expression, it was measured whether they would follow the proposed treatment, wanted to make such decision, wanted to be hospitalized, and thought they were entitled to make such decision to be hospitalized. In this regard, they were given 4 items, asked to give yes/ no to each item. If they could give any answer, they were given 1 point; if not, they were given 0 point. To assess the competence of reasoning, they were asked in 6 items about why they gave yes or no to each item. Specifically, they were asked about why they made such decision and which influence they thought such decision would have. Each item was rated in $0-1$ point or $0-2$ points, so the total marks ranged from 0 to 8 .

\section{Statistical analysis}

SPSS 15.0 for windows and AMOS 7.0 program were used to make descriptive statistical analysis, correlation coefficient analysis, Cronbach's alpha analysis, ICC analysis, factor analysis, confirmatory factor analysis, Receiver Operating Characteristic (ROC) analysis etc, which are used to develop the tools to decide the hospitalization consent competences of mental disease patients.

\section{Reliability test}

This study checked the ICC and Cronbach's alpha between raters.

\section{Construction validation}

AMOS 7.0 program was used to verify model appropriateness, i.e. whether the developed evaluation tool is made in a way theoretically hypothesized. Kline ${ }^{25}$ says that at least 4 of chisquare, comparative fit index (GFI), NFI, CFI, non-normed fit index (NNFI), standardized root mean residual (SRMR), overall appropriateness indexes, to assess the model hypothesized by researchers, and other researchers recommend that chisquare, AGFI, TLI (NNFI), RMSEA should be used. In particular, RMSEA and CFI indexes are less sensitive to sample sizes, compared to other indexes ${ }^{26}$ Accordingly, this study tested the construction validity of a tool developed by calculating out $\chi^{2}$, CFI, TLI, GFI and RMSEA values.

\section{Criterion-related validation}

This study analyzed whether the developed tool was correlated to Korean Version of Mini-Mental State Examination points, 
insight, estimated intelligence and BPRS.

\section{Efficiency test of the evaluation tool}

To verify the efficiency of this tool, this study used the ROC Curve calculated out between the groups judged to be competence and incompetence by the expert panel and the relevant indexes. This curve, used to assess the accuracy of diagnostic classification, offers a graph of true positive rate, sensitivity vs. false positive rate, 1.0-specificity. The Area under Curve (AUC) shows the efficiency of assessment: the broader area is, the more efficient assessment is. Based on the assessment efficiency of the tool developed, the optimum cutoff point was decided to distinguish the people with consent competence and the people without consent competence.

\section{RESULTS}

\section{Descriptive statistics}

Means, standard error of means (SEM) and standard deviation of KATOC and criterion variables used in this study were calculated. In the Wechsler's intelligence scale, the average intelligence of subjects was 91.31 (SEM=2.14, $\mathrm{SD}=20.28)$, showing an intellectual ability of normal range. KATOC full scale's means, SEM, and SD were 27.12, 0.72, 7.10, respectively. KATOC subscale understanding means was 6.65 (SEM=0.30, $\mathrm{SD}=2.98$ ); appreciation 10.77 ( $\mathrm{SEM}=0.30, \mathrm{SD}=2.98$ ); expression of a choice $3.81(\mathrm{SEM}=0.06, \mathrm{SD}=0.57)$; reasoning ability $5.90(\mathrm{SEM}=0.20, \mathrm{SD}=2.01)$. Criterion variables' means were as follows; MMSE 25.67 (SEM=0.31, SD=3.10), Insight 21.19 $(\mathrm{SEM}=0.58, \mathrm{SD}=5.71)$, BPRS 31.76 (SEM=1.57, $\mathrm{SD}=15.54)$.

\section{Reliability and validity}

Table 1 shows the results obtained by determining the reliability of hospitalization consent competence scales of mental disease patients with ICC and Cronbach's alpha. As seen in the table, the analysis of the reliability between raters in the absolute agreement type of dual mixed model (participant random variable/rater fixed variable) showed a high level of agreement between raters, as ICC, appreciation, expression, and reasoning were $0.859-0.983,0.671-0.90,0.78-1.00$ and $0.70-0.80$ respectively in terms of understanding subscale. The ICC for total scale was 0.94 , showing a very good agreement rate. In terms of the internal consistency coefficients for total scale and 4 subscales of hospitalization consent competence, the total scale, i.e. understanding, appreciation, expression of choice and reasoning were 0.87 , $0.77,0.81,0.70$ and 0.70 respectively, showing satisfactory levels.

The hospitalization consent competence scales for mental disease patients developed by researchers was validated through the procedures of construction validation and criterion-related validation. First, in terms of construction validation, it was checked how appropriate it was to compose the scales of hospitalization consent competence proposed by researchers of 4 subscales. As a result, the appropriateness levels of a 4 -factor model showed $\chi^{2}=72.40$, GFI $=0.90$, TLI (NNFI) $=0.95, \mathrm{CFI}=0.96$, RMSEA $=0.05$ and SRMR $=0.08$. Such indexes show the fourfactor structure model hypothesized in this study according to the model appropriateness standards proposed by $\mathrm{Hu}$ and Bentler ${ }^{27}$ to assess the appropriateness of the factor structure hypothesized in the confirmatory factor analysis. Specifically, they reported that the confirmatory factor analysis results well reflect the factor structure proposed by researchers, when CFI, NNFI and SRMR are $>0.95$, and $<0.08$. Schumacker and Rich$\operatorname{ard}^{28}$ reported that the model is good, when RMSEA is $<0.05$ and appropriate, when RMSEA is 0.08 or less. Hu and Bentler ${ }^{29}$ proposed RMSEA less than equal 0.06 as a criterion for good model appropriateness.

All factor loadings were statistically significant. Such results show that construction validity is seen in the hospitalization consent competence test of mental disease patients proposed by researchers.

In the meantime, this study checked the correlation between the marks of the test and the criterion-related variables. As seen in Table 2, the total score of hospitalization consent competence was related to intelligence, insight and mental state, but showed no significant correlation with BPRS. Also, in the correlation between subscales and criterion-related variables, the scales of understanding, appreciation and reasoning showed no significant correlation with intelligence, insight and mental state points, but the subscale of a choice showed no significant correlation with any criterion-related variable.

\section{Efficiency of tool}

The efficiency of the developed tool in determining whether a mental disease patient has hospitalization consent competence was checked using the ROC Curve calculated out between the group $(\mathrm{n}=27)$ judged to have no consent decision ability and the group $(n=25)$ judged to have consent decision ability and the relevant indexes. This curve, used to assess the accuracy of diagnosis examination, offers a graph of true positive rate, sensitivity vs. false positive rate, 1.0-specificity. The AUC shows the efficiency of tool: the broader area is, the more efficient evaluation is. Fig. 1 and Table 3, 4 show the ROC analysis results. The AUC of total score of hospitalization consent competences was 0.733 , showing a statistical significance $(p=0.004)$. However, the subscales of appreciation ( $\mathrm{AUC}=0.726, \mathrm{p}=0.005)$ and reasoning ( $\mathrm{AUC}=0.662, \mathrm{p}=0.043$ ) in the efficiency for subscales were significant in distinguishing between the people with consent competences and the people without consent competences, and understanding and expression were not significant. Such results indicate that understanding and expression are 
basic competences that understanding and expression need to decide hospitalization. When there are competences of these two areas, the evaluation of appreciation and reasoning can be valid.
Accordingly, this study proposes that the cutoff points of understanding and expression should be more than the total mean values of the groups with and without hospitalization consent com-

Table 1. Item statistics, the ICC, and Cronbach's Alpha for KATOC subscales

\begin{tabular}{|c|c|c|c|c|c|c|}
\hline Subscales & Items & Mean & $\begin{array}{l}\text { Standard } \\
\text { deviation }\end{array}$ & $\begin{array}{l}\text { Corrected item- } \\
\text { total correlation }\end{array}$ & $\begin{array}{c}\text { Cronbach's alpha if } \\
\text { item deleted }\end{array}$ & ICC \\
\hline \multirow[t]{6}{*}{ Understanding } & Understanding of mental disorder symptoms & 1.29 & 0.723 & 0.587 & 0.714 & 0.887 \\
\hline & Understanding of proposed treatment & 1.60 & 0.771 & 0.579 & 0.715 & 0.983 \\
\hline & Understanding of treatment advantages & 1.24 & 0.834 & 0.514 & 0.736 & 0.866 \\
\hline & Problems in non-treatment & 1.40 & 0.821 & 0.531 & 0.730 & 0.859 \\
\hline & Additional advantages of hospitalized treatment & 1.14 & 0.897 & 0.506 & 0.742 & 0.912 \\
\hline & Cronbach's Alpha $=0.77$ & & & & & \\
\hline \multirow[t]{8}{*}{ Appreciation } & Applicability to one's own symptoms & 1.81 & 0.486 & 0.490 & 0.794 & 0.671 \\
\hline & Necessity of treatment to one's own symptoms & 1.55 & 0.776 & 0.561 & 0.780 & 0.887 \\
\hline & Application of reasoning to medical treatment & 1.48 & 0.752 & 0.484 & 0.795 & 0.878 \\
\hline & Improvement due to levels of treatment & 1.43 & 0.709 & 0.549 & 0.782 & 0.870 \\
\hline & One's own problems in case of non-treatment & 1.59 & 0.663 & 0.560 & 0.780 & 0.900 \\
\hline & $\begin{array}{l}\text { Necessity of hospitalized treatment to one's own } \\
\text { symptoms }\end{array}$ & 1.46 & 0.683 & 0.613 & 0.770 & 0.706 \\
\hline & $\begin{array}{l}\text { Improvement levels of symptoms after } \\
\text { hospitalized treatment }\end{array}$ & 1.37 & 0.714 & 0.575 & 0.777 & 0.782 \\
\hline & Cronbach's Alpha $=0.81$ & & & & & \\
\hline \multirow{5}{*}{$\begin{array}{l}\text { Expression of } \\
\text { a choice }\end{array}$} & Selection of medical treatment recommendations & 0.97 & 0.169 & 0.461 & 0.667 & 0.853 \\
\hline & Autonomous decision regarding treatment & 0.88 & 0.322 & 0.587 & 0.567 & 0.780 \\
\hline & $\begin{array}{l}\text { Autonomous decision regarding hospitalized } \\
\text { treatment }\end{array}$ & 0.95 & 0.216 & 0.415 & 0.674 & 1.00 \\
\hline & $\begin{array}{l}\text { Autonomous decision-making right } \\
\text { to hospitalization }\end{array}$ & 0.90 & 0.298 & 0.549 & 0.590 & 0.890 \\
\hline & Cronbach's Alpha $=0.70$ & & & & & \\
\hline \multirow{7}{*}{$\begin{array}{l}\text { Reasoning } \\
\text { ability }\end{array}$} & Reasons for treatment decision & 1.52 & 0.624 & 0.424 & 0.665 & 0.718 \\
\hline & Influence of treatment decision on oneself & 0.77 & 0.425 & 0.484 & 0.648 & 0.806 \\
\hline & $\begin{array}{l}\text { Influence of treatment decision on human } \\
\text { relations and social life }\end{array}$ & 0.69 & 0.465 & 0.519 & 0.634 & 0.739 \\
\hline & Reasons for hospitalization decision & 1.57 & 0.636 & 0.262 & 0.726 & 0.716 \\
\hline & Influence of hospitalization decision on oneself & 0.66 & 0.476 & 0.502 & 0.638 & 0.700 \\
\hline & $\begin{array}{l}\text { Influence of hospitalization decision on human } \\
\text { relations and social life }\end{array}$ & 0.66 & 0.476 & 0.488 & 0.643 & 0.749 \\
\hline & Cronbach's Alpha $=0.70$ & & & & & \\
\hline
\end{tabular}

Table 2. Pearson correlations between admission competency and criterion variables

\begin{tabular}{llccc}
\hline Admission competency & IQ & BPRS & Insight & MMSE \\
\hline Full scale & $0.345^{\dagger}$ & -0.105 & $0.412^{\dagger}$ & $0.424^{\dagger}$ \\
Subscale understanding & $0.272^{\dagger}$ & -0.147 & $0.212^{*}$ & $0.425^{\dagger}$ \\
Appreciation & $0.323^{\dagger}$ & -0.058 & $0.433^{\dagger}$ & $0.355^{\dagger}$ \\
Expression of a choice & 0.035 & -0.016 & 0.033 & -0.008 \\
Reasoning ability & $0.264^{\dagger}$ & -0.051 & $0.409^{\dagger}$ & $0.281^{\dagger}$ \\
\hline
\end{tabular}

${ }^{*}$ correlation is significant at the 0.05 level (2-tailed), ${ }^{\dagger}$ correlation is significant at the 0.01 level (2-tailed) 
Table 3. Area under the curve in $\mathrm{ROC}$ analysis

\begin{tabular}{|c|c|c|c|c|c|}
\hline \multirow{2}{*}{ Test result variables } & \multirow{2}{*}{ Area } & \multirow{2}{*}{ Std. Error* } & \multirow{2}{*}{ Asymptotic Sig. ${ }^{\dagger}$} & \multicolumn{2}{|c|}{ Asymptotic $95 \%$ confidence interval } \\
\hline & & & & \multicolumn{2}{|c|}{ Lower bound upper bound } \\
\hline Full scale & 0.733 & 0.070 & 0.004 & 0.595 & 0.871 \\
\hline Subscale understanding & 0.602 & 0.078 & 0.203 & 0.449 & 0.755 \\
\hline Appreciation & 0.726 & 0.071 & 0.005 & 0.586 & 0.866 \\
\hline Expression of a choice & 0.549 & 0.079 & 0.539 & 0.394 & 0.705 \\
\hline Reasoning ability & 0.662 & 0.075 & 0.043 & 0.515 & 0.809 \\
\hline
\end{tabular}

${ }^{*}$ under the nonparametric assumption, ${ }^{\dagger}$ null hypothesis: true area $=0.5$

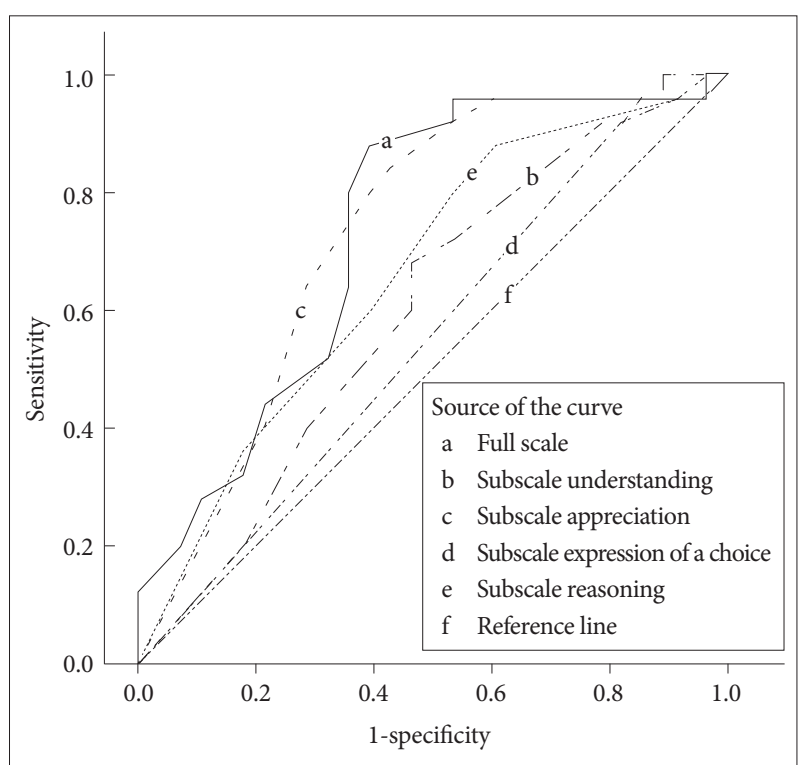

Figure 1. The Receiver Operating Characteristic Curve, in which the sensitivity is plotted against 1-specificity for various possible settings of the cutoff score.

petences and that those of appreciation and reasoning should be the points that have maximum accuracy based on ROC analysis.

First, the mean value of understanding and expression are 6.65 and 3.81 respectively. Accordingly, the cutoff points of understanding and expression are 6.65 and 3.81 respectively. According to the ROC analysis results, accuracy is 0.71 , when the sensitivity and specificity of this scale are 0.84 and 0.57 respectively. Accordingly, the appreciation value with an accuracy of 0.71 is 10.5 . When adopting this value as a cutoff point, the efficiency of test is optimal. When its value is 4.5 , the competence of reasoning is the highest, with sensitivity, specificity and accuracy having $0.88,0.39$ and 0.64 respectively. Accordingly, when adopting 4.5 with an accuracy of 0.64 as a cutoff point of reasoning, the efficiency of test is optimal.

In short, when understanding, expression, appreciation and reasoning meet the conditions of 6.65 points or more, 3.81 points or more, 10.5 points or more and 4.5 or more respectively, its is judged that there is consent competence; if there is even one scale lower than the cutoff points of the four scales, it is judged that there is no consent competence.

\section{DISCUSSION}

The Korean Tool of Competency to Consent to Psychiatric Hospitalization based on MacCAT-T shows that the agreement between raters is relatively high, as seen in the values from 0.831 to 0.958 and that the inner consistency coefficient is reliable, as seen in the values from 0.908 to 0.979 . This is relatively high, as compared to the fact the agreements of two raters for MacCATT range from 0.33 to 0.71 according to Crains et al. ${ }^{20}$ Also, the confirmatory factor analysis for constructive validation shows that the tool is valid, and the MMSE, BPRS, IQ and insight tests for criterion related validation shows that IQ, insight and MMSE are significantly correlated to understanding, appreciation and reasoning. The higher IQ, insight and MMSE scores were, the higher understanding, appreciation and reasoning competences were. However, competence to express a choice did not show any significant correlation with criterion variables, nor showed BPRS any significant correlation with sub-competences. Also, the correlation with consent sub-competences showed that understanding, appreciation and reasoning were statistically related to each other and that reasoning and appreciation had high correlation coefficients. However, the competence of expression showed any significant correlation with those of appreciation and reasoning, but no significant correlation with the competence of understanding.

Such results correspond to those which the consent sub-competences measured with MacCAT-T are related to MMSE ${ }^{12}$ and insight. ${ }^{1}$ In particular, the competence of understanding shows a middle level of correlation with MMSE and IQ, which corresponds with the argument of Appelbaum and Roth ${ }^{30}$ that the competence of understanding is influenced by orientation, concentration, memory etc. Appreciation and reasoning show correlation of middle level or higher with insight. Showing that one accepts the existence of their mental illness, insight is closely related to the appreciation that is judged based on the recognition level of one's own disorder. This corresponds with the re- 
Table 4. Coordinates of the curve in the KATOC

\begin{tabular}{|c|c|c|c|}
\hline $\begin{array}{c}\text { Test result } \\
\text { variable(s) }\end{array}$ & $\begin{array}{l}\text { Positive if greater } \\
\text { than or equal to(a) }\end{array}$ & Sensitivity & 1-specificity \\
\hline \multirow[t]{22}{*}{ Full scale } & 8.00 & 1.000 & 1.000 \\
\hline & 10.00 & 1.000 & 0.964 \\
\hline & 12.00 & 0.960 & 0.964 \\
\hline & 15.00 & 0.960 & 0.929 \\
\hline & 17.50 & 0.960 & 0.821 \\
\hline & 19.00 & 0.960 & 0.786 \\
\hline & 20.50 & 0.960 & 0.750 \\
\hline & 22.00 & 0.960 & 0.679 \\
\hline & 23.50 & 0.960 & 0.536 \\
\hline & 24.50 & 0.920 & 0.536 \\
\hline & 25.50 & 0.880 & 0.393 \\
\hline & 26.50 & 0.800 & 0.357 \\
\hline & 27.50 & 0.760 & 0.357 \\
\hline & 28.50 & 0.720 & 0.357 \\
\hline & 29.50 & 0.640 & 0.357 \\
\hline & 30.50 & 0.520 & 0.321 \\
\hline & 31.50 & 0.440 & 0.214 \\
\hline & 32.50 & 0.320 & 0.179 \\
\hline & 33.50 & 0.280 & 0.107 \\
\hline & 34.50 & 0.200 & 0.071 \\
\hline & 35.50 & 0.120 & 0.000 \\
\hline & 37.00 & 0.000 & 0.000 \\
\hline \multirow{11}{*}{$\begin{array}{l}\text { Subscale } \\
\text { understanding }\end{array}$} & 0.50 & 1.000 & 0.893 \\
\hline & 1.50 & 0.960 & 0.893 \\
\hline & 2.50 & 0.960 & 0.857 \\
\hline & 3.50 & 0.920 & 0.821 \\
\hline & 4.50 & 0.920 & 0.786 \\
\hline & 5.50 & 0.720 & 0.536 \\
\hline & 6.50 & 0.680 & 0.464 \\
\hline & 7.50 & 0.600 & 0.464 \\
\hline & 8.50 & 0.400 & 0.286 \\
\hline & 9.50 & 0.200 & 0.179 \\
\hline & 11.00 & 0.000 & 0.000 \\
\hline \multirow{10}{*}{$\begin{array}{l}\text { Subscale } \\
\text { appreciation }\end{array}$} & 1.00 & 1.000 & 1.000 \\
\hline & 2.50 & 0.960 & 0.964 \\
\hline & 4.00 & 0.960 & 0.929 \\
\hline & 5.50 & 0.960 & 0.893 \\
\hline & 6.50 & 0.960 & 0.750 \\
\hline & 7.50 & 0.960 & 0.714 \\
\hline & 8.50 & 0.960 & 0.607 \\
\hline & 9.50 & 0.920 & 0.536 \\
\hline & 10.50 & 0.840 & 0.429 \\
\hline & 11.50 & 0.800 & 0.393 \\
\hline
\end{tabular}

Table 4. Continued

\begin{tabular}{cccc}
\hline $\begin{array}{c}\text { Test result } \\
\text { variable(s) }\end{array}$ & $\begin{array}{c}\text { Positive if greater } \\
\text { than or equal to(a) }\end{array}$ & Sensitivity & 1-specificity \\
\hline Subscale & 12.50 & 0.640 & 0.286 \\
appreciation & 13.50 & 0.400 & 0.214 \\
Subscale & 15.00 & 0.000 & 0.000 \\
expression & 1.00 & 1.000 & 0.964 \\
of a choice & 2.50 & 0.960 & 0.929 \\
& 3.50 & 0.920 & 0.821 \\
Subscale & 5.00 & 0.000 & 0.000 \\
reasoning & 0.00 & 1.000 & 1.000 \\
ability & 1.50 & 1.000 & 0.964 \\
& 2.50 & 0.960 & 0.929 \\
& 3.50 & 0.920 & 0.750 \\
& 4.50 & 0.880 & 0.607 \\
& 5.50 & 0.800 & 0.536 \\
& 6.50 & 0.600 & 0.393 \\
& 7.50 & 0.360 & 0.179 \\
& 9.00 & 0.000 & 0.000 \\
\hline
\end{tabular}

The test result variable(s): full scale and subscales has at least one tie between the positive actual state group and the negative actual state group. a The smallest cutoff value is the minimum observed test value minus 1 , and the largest cutoff value is the maximum observed test value plus 1 . All the other cutoff values are the averages of two consecutive ordered observed test values

sult that insight is the most powerful predictor to decide the competence and incompetence to consent. ${ }^{1}$

However, this study shows that BPRS is not significantly related to consent sub-competences. Such result is different from the results that BPRS scores are higher in the group of incompetence $^{1}$ and that the Severity of Psychiatric Illness Scale and Acuity of Psychiatric Illness Scale scores were significantly low in the group of competence, when measuring the competence and incompetence to consent to hospitalization using the Competency Questionnaire. ${ }^{8}$ Carpenter et al. ${ }^{14}$ reported that understanding and reasoning showed negative correlation with BPRS, when measuring consent ability with MacCAT-T. However, this result corresponds with the results that the treatment consent ability does not vary according to the clinical variables, i.e. diagnosis, symptom, hospitalization duration and frequency. ${ }^{20,31}$ Also, it is difficult to think that psychiatric symptoms predict consent competence, because understanding also has negative correlation only with thought disorder of BPRS in the study that analyzes the relationships between consent ability and BPRS. Our study shows that it is possible to interpret in two ways that consent ability shows no significant correlation with BPRS. First, one interpretation is to admit that consent ability of a patient is not related to psychiatric symptoms. Admitting such result, it is very dangerous to assess consent ability only with clini- 
cal variables, so one should emphasize that it is very important for clinicians to make efforts to assess consent ability separately from clinical variables. Second, the average BPRS scores of the subjects is not high, as seen in 31.26. This is because the study targeted the patients hospitalized and their duration of hospitalization was 17.67 months on the average, showing symptoms were somewhat controlled. Accordingly, it is expected that results will change, if the consent competence assessment is regularly implemented during the hospitalization with symptoms clinically uncontrolled.

In terms of correlation between consent sub-competences, this study shows that the $r$ values between sub-competences except the correlation between expression competences were $0.212-0.657$, showing static correlation. In particular, appreciation showed high correlations of 0.505 and 0.657 with understanding and reasoning respectively. However, Vollman et al. ${ }^{12}$ showed that understanding and reasoning had a high correlation of 0.50 or more, but had a middle correlation of 0.34 to 0.37 with appreciation. Palmer et al. ${ }^{31}$ also showed that understanding and appreciation had a middle correlation, as seen in $r$ coefficient of $0.685,0.535$ and 0.472 in understanding and appreciation, reasoning and appreciation, and understanding and reasoning respectively. Such results emphasize that it is important to make an area-specific assessment, as the competence in an area is not unrelated to that in another area, but the incompetence in an area does not enable to wholly predict that in another area.

In addition, this study showed that expression had no significant correlation with criterion-related variables. This is because subjects were 3.81 on the mean in expression score, approaching 4, maximum point. Vollman et al. ${ }^{12}$ argued that it was difficult to significantly consider expression in assessing consent competence, as the assessment of treatment consent competence using MacCAT-T showed most of the subjects in dementia, depression and schizophrea groups got full credit in expression. Palmer et $\mathrm{al}^{31}$ showed that expression was excluded from the correlation analysis of sub-competences, as only one of 16 patients did not get maximum score in expression. According to Grisso and Appelbaum, ${ }^{10}$ the assessment of treatment consent competence showed that less than $5 \%$ of a total of 498 subjects of schizophrenia, depression, angina, community sample etc were judged to lack in expression, showing no difference by diagnosis, patient or community sample. Accordingly, expression is a minimum criterion in overall consent competence assessment. If one is judged to have no ability to express a choice, one will be able to be regarded as having no overall consent competence regardless of competence levels in other areas.

Vollmann et al. ${ }^{12}$ presented area-specific cutoffs as the standards to dichotomized in categories 'impaired'/'unimpaired' based on MacCAT-T and saw consent competence as lacking, if even one of areas is judged to be incompetent. Our study also intends to think that one has the competency to consent to psychiatric hospitalization impaired if one gets a mark lower than cutoff in any one of four areas. Specifically, in our study the patients are judged to have consent competence if they get marks higher than the following cutoff scores all four scales (understanding 6.65, expression 3.81, appreciation 10.5 and reasoning 4.5). However, they are considered as incompetence if they have mark less than cutoff score in any one area.

Implication. Our study developed the Korean Tool of Competency to Consent to Psychiatric Admission Treatment in the Mentally Ill, verified the reliability and validity of the tool and analyzed the optimum cutoff to distinguish between competence and incompetence in sub-competences. Korean Assessment Tool of Competence to Consent to Psychiatric Hospitalization, analyzed the reliability and validity of this tool and presented the cutoff points by subarea. As a result, the reliability and validity of satisfactory levels were verified, the ROC analysis was implemented based on the clinical assessment and the cutoff points were found in understanding, appreciation, expression of a choice and reasoning. Such findings showed that the tool developed by researchers could be very favorably used in Korea where $90 \%$ or more of hospitalized patients are coercive admitted to hospital based on the mere clinical judgment without objective assessment tool. In particular, as psychiatric symptoms show no significant correlation with consent sub-competences, it is difficult to effectively distinguish between consent competence and incompetence with clinical judgment alone, so it is more necessary to develop an objective assessment tool.

It is expected that a involuntary hospitalization will significantly decrease if the forced admission is limited to incompetence judged with an objective tool; if involuntary hospitalization is unavoidable, the more ethical practice of clinicians will be more strengthened by demonstrating the incompetence of the patient involved. Also, the findings showed that the consent competence of a patient is not one dimensional, so it is possible to diminish the malpractice of generalizing the incompetence in one area into those in other areas.

However, this study is limited in selecting subjects. First, all of the subjects consented to the participation in the study and had their symptoms controlled in hospitalization, so the study excluded the patients whose psychiatric symptoms were serious or had a very low consent competence from the beginning. Also, $73.55 \%$ of subjects had schizophrenia, making it difficult to make a diagnosis-specific comparison. Accordingly, it is necessary to verify the efficiency of the tool that can generalize patients with various diagnoses in the following studies. In addition, this study developed a tool to assess hospitalization consent competence for hospitalized patients, so it is expected that another tool will be developed that can be used for various areas 
such as treatment consent competence and study participation consent competence and for outpatients. Moreover, as consent competences themselves can be changed and improved by personal psychosocial circumstances, ${ }^{1}$ it is necessary to search for the factors that can promote the improvement of competences and to present the measures to strengthen them, through the longitudinal survey of the changes in consent competence.

\section{Acknowledgments}

This study was supported by a research grant from the Korean Government (MOEHRD), Basic Research Promotion Fund (KRF-2008-321-B00138).

\section{REFERENCES}

1. Cairns R, Meddock C, Buchanan A, David AS, Hayward P, Richardson G, et al. Reliability of mental capacity assessments in psychiatric in-patients. Br J Psychiatry 2005;187:372-378.

2. WHO. Guidelines For The Promotion of Human Rights of Persons with Mental Disorders; 1996.

3. Data on Inspection of Government Offices. Homepage of Lawmaker Kim, Chun-jin, National Assembly Commissioner for Health Care and Welfare: http://www.cjkorea.org/zbxe/mmt3_1/12320/page/82; 2007.

4. Grisso T, Appelbaum PS. Mentally ill and non-mentally-ill patients' abilities to understand informed consent disclosures for medication: preliminary data. Law Hum Behav 1991;15:377-388.

5. Appelbaum PS. Assessment of patients' competence to consent to treatment. N Engl J Med 2007;357:1834-1840.

6. Dunn LB, Nowrangi MA, Palmer BW, Jeste DV, Saks ER. Assessing decisional capacity for clinical research or treatment: a review of instruments. Am J Psychiatry 2006;163:1323-1334.

7. Sturman ED. The capacity to consent to treatment and research: a review of standardized assessment tools. Clin Psychol Rev 2005;25:954-974.

8. Fraguas D, García-Solano F, Chapela E, Terán S, de la Peña JJ, CalcedoBarba A. Do psychiatric patients improve their competency to consent to hospitalization after admission? A prospective study in an acute inpatient ward. Gen Hosp Psychiatry 2007;29:54-62.

9. Kitamura F, Tomoda A, Tsukada K, Tanaka M, Kawakami I, Mishima S, et al. Method for assessment of competency to consent in the mentally ill. Rationale, development, and comparison with the medically ill. Int J Law Psychiatry 1998;21:223-244.

10. Grisso T, Appelbaum PS. The MacArthur Treatment Competence Study. III: Abilities of patients to consent to psychiatric and medical treatments. Law Hum Behav 1995;19:149-174.

11. Grisso T, Appelbaum PS. Comparison of standards for assessing patients' capacities to make treatment decisions. Am J Psychiatry 1995;152:10331037.

12. Vollmann J, Bauer A, Danker Hopfe H, Helmchen H. Competence of mentally ill patients: a comparative empirical study. Psychol Med 2003; 33:1463-1471.

13. Kim SY, Caine ED. Utility and limits of the mini mental state examination in evaluating consent capacity in Alzheimer's disease. Psychiatr Serv
2002;53:1322-1324.

14. Carpenter WT Jr, Gold JM, Lahti AC, Queern CA, Conley RR, Bartko JJ, et al. Decisional capacity for informed consent in schizophrenia research. Arch Gen Psychiatry 2000;57:533-538.

15. Palmer BW, Dunn LB, Depp CA, Eyler LT, Jeste DV. Decisional capacity to consent to research among patients with bipolar disorder: comparison with schizophrenia patients and healthy subjects. J Clin Psychiatry 2007;68:689-696.

16. Barton CD Jr, Mallik HS, Orr WB, Janofsky JS. Clinicians' judgement of capacity of nursing home patients to give informed consent. Psychiatr Serv 1996;47:956-960.

17. Appelbaum PS, Grisso T. The MacArthur Treatment Competence Study. I: Mental illness and competence to consent to treatment. Law Hum Behav 1995;19:105-126.

18. Bean G, Nishisato S, Rector NA, Glancy G. The psychometric properties of the Competency Interview Schedule. Can J Psychiatry 1994;39:368376.

19. Grisso T, Appelbaum PS. Assessing Competence to Consent to Treatment: A Guide for Physicians and Other Health Professionals. New York: Oxford University Press; 1998.

20. Cairns R, Maddock C, Buchanan A, David AS, Hayward P, Richardson G, et al. Prevalence and predictors of mental incapacity in psychiatric inpatients. Br J Psychiatry 2005;187:379-385.

21. Kwon YC, Park JH. Korean Version of Mini-Mental State Examination (MMSE-K) Part I : developement of the test for the elderly. J Korean Neuropsychiatr Assoc 1989;28:125-135.

22. David AS. Insight and psychosis. Br J Psychiatry 1990;156:798-808.

23. Yeom TH, Park YS, Oh JJ, Kim JK, Lee YH. Manual of K-WAIS, Korea Guidence; 1992.

24. Overall JE, Gorham DR. The brief psychiatric rating scale. Psychol Rep 1962;10:799-812.

25. Kline RB. Principles and practice of structural equation modeling: A very readable introduction to the subject, with good coverage of assumptions and SEM's relation to underlying regression, factor, and other techniques. NY: Guilford Press; 1998.

26. Fan X, Thompson B, Wang L. Effects of sample size, estimation method, model specification on structural equation modeling fit indexes. Struct Equ Modeling 1999;6:56-83.

27. Hu LU, Bentler PM. Fit indices in covariance structure modeling: sensitivity to underparameterized model misspecification. Psychol Methods 1998;3:424-453.

28. Schumacker RE, Richard GL. A beginner's guide to structural equation modeling, Second edition. Mahwah, NJ: Lawrence Erlbaum Associates; 2004.

29. Hu LU, Bentler PM. Cutoff criteria for fit indexes in covariance structure analysis: Conventional criteria versus new alternatives. Struct Equ Modeling 1999;6:1-55.

30. Appelbaum PS, Roth LH. Competency to consent to research: a psychiatric overview. Arch Gen Psychiatry 1982;39:951-958.

31. Palmer BW, Nayak GV, Dunn LB, Appelbaum PS. Treatment-related decision-making capacity in middle-aged and older patients with psychosis: a preliminary study using the MacCAT-T and HCAT. Am J Geriatr Psychiatry 2002;10:207-211. 